\title{
A tribute to Dr. Teresa Pinto-Hamuy
}

This issue of Biological Research is dedicated to Teresa Pinto-Hamuy, who was a distinguished and influential Chilean neuroscientist. We have invited several of Teresa's students and collaborators that are active in her area of research to participate in this memorial issue. We all have the feeling that this tribute settles a debt we had with her after her death.

She was a woman who lived ahead of

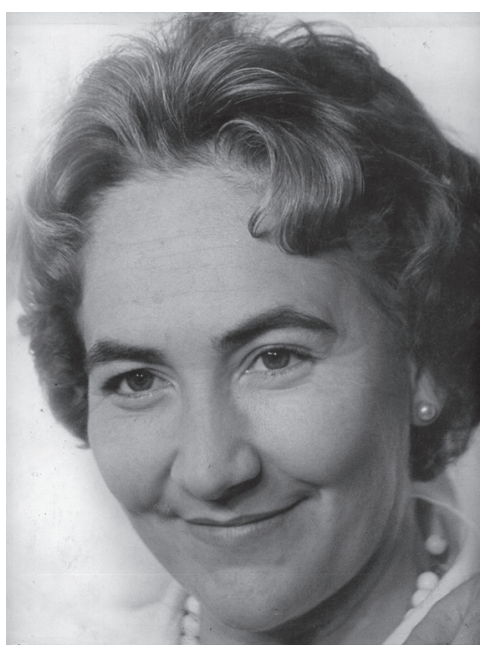
her times. She studied medicine at a time when this was an unusual profession for women and, moved by her intellectual curiosity, she decided to dedicate her life to scientific research, which was still more unusual. Immediately after receiving her MD degree from the University of Chile, she started working at the recently created Institute of Physiology of the University of Chile, headed by Dr. Francisco Hoffman. She completed her training in physiological psychology with postdoctoral research periods at Johns Hopkins, Wisconsin and Stanford Universities. There she received the influence of some of the leading neuroscientists at that time, Phillip Bard, Clinton Woolsey, Karl Lashley, Harry Harlow and Jerzy Rose.

After her return to Chile she became a pioneer in the area of physiological psychology, setting up the first research laboratory in that field in the country and in the region. From the Department (now Program) of Physiology and Biophysics, she made a great contribution to the development of Cognitive Neuroscience in the University of Chile and in the country. From the beginning of her career and throughout her life, she established productive scientific collaborations with the most outstanding scientists working in the area of brain and behavioural studies. She was visiting professor at several universities in the USA and Europe, was awarded several international grants and published her research in the best journals.

With great enthusiasm and dedication she trained various generations of young investigators coming from the Faculty of Medicine, as well as from the Faculty of Social Sciences, where she had an extensive career as a Professor. During that time, she directed many students in their research projects, always guiding them in a rigorous approach to their research problems. Because of her character, most of her students developed a close friendship with her. The neuroscientists collaborating in this issue are some of these disciples who became her friends. We only regret that, for various reasons, some of her closest collaborators could not contribute to this issue.

As a result of her numerous contributions to her field of research, her research group became a referent in Latin America. She also had a 
special commitment to teaching activities, giving lectures that were inspiring to students. She created a course in physiological psychology, which she taught for many years at the School of Psychology of the University of Chile, emphasizing the importance of biological processes in psychology. During the early

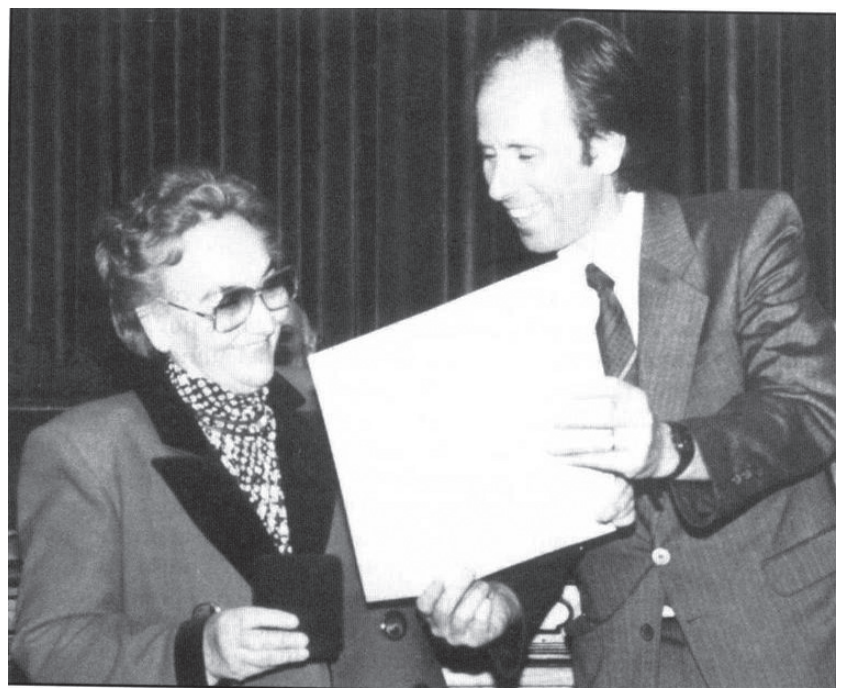
seventies, when the university was under military rule, she was informed one day by one of her students that she was not professor at the School of Psychology any more. In spite of this, many of the students from that school kept coming to work on their thesis projects under her direction in her laboratory at the Faculty of Medicine.

As a modest person, she never mentioned several distinctions that she had received. Among them, she was awarded a Guggenheim Foundation scholarship in 1961 to work at Stanford University with Dr. Karl Pribram and in 1990 she received the Amanda Labarca award that distinguishes university women for outstanding contributions to the sciences and humanities.

As a person, she had warm and attractive personality, a true interest in all aspects of culture and a great intellectual curiosity. One could say that she characterized better than anybody the ideals and principles of the University of Chile: humanism, pluralism, freedom of thought and expression, and commitment to the community.

DR. LUIS ROBLES

Guest Editor
DR. FERNANDO TORREALBA

Guest Editor

DR. MANUEL SANTOS

Editor-in-Chief(S) 